https://doi.org/10.11646/zootaxa.4254.1.6

http://zoobank.org/urn:lsid:zoobank.org:pub:FAD163BA-AC22-4AFE-8FF0-7E9FBDDDC6B3

\title{
A new species of Pamphagus (Orthoptera: Pamphagidae) from Algeria with a key to all the species of the genus
}

\author{
NAIMA BENKENANA ${ }^{1} \&$ BRUNO MASSA ${ }^{2,3}$ \\ ${ }^{\prime}$ Laboratoire de Biosystématique et Ecologie des Arthropodes, Université Mentouri, Constantine, route d'Aïn-El-Bey, 25000, Constan- \\ tine, Algérie.E-mail: benkenanan@yahoo.co.nz \\ ${ }^{2}$ Department of Agriculture and Forest Sciences, University of Palermo, Viale Scienze 13, 90128 Palermo, Italy. \\ E-mail: bruno.massa@unipa.it \\ ${ }^{3}$ Corresponding author
}

\begin{abstract}
The authors describe Pamphagus milevitanus n. sp. occurring in the North and South highlands of Constantine, in Mila, Setif and Oum-el Bouaghi provinces, where it is fairly common. They compare the characters of this species with those of the most related species of the genus and present a complete plate and a key to all the species of the genus Pamphagus known to date.
\end{abstract}

Key words: Pamphagus milevitanus n. sp., North Africa, Mila Region, key to species

\section{Introduction}

Eleven species in the genus Pamphagus Thunberg, 1815 are currently known; six of these are present in Algeria, namely: P. auresianus Massa, 1992 and P. batnensis Benkenana \& Petit, 2012 in the Aurés Mts, P. caprai Massa, 1992 in the most western part of North Algeria and North-East Morocco, P. elephas (Linnaeus, 1758) in the central part of North Algeria, P. cristatus Descamps \& Mounassif, 1972 in the most eastern part of North Algeria and North Tunisia (Krumiria), and $P$. djelfensis Vosseler, 1902 in the Djelfa highlands [the record from Belezma by Benkenana et al. (2012) needs to be confirmed]. The other five species are not known from Algeria [P. tunetanus Vosseler, 1902 in Tunisia and Libya, P. meridionalis Descamps \& Mounassif, 1972 in South Tunisia (Massa et al. (1993) found a high variability of this taxon, a possible synonym of $P$. tunetanus), P. ortolanii Massa \& Cusimano, 1977 in the islet of Lampedusa, Italy, P. sardeus (Herrich-Schäffer, 1840) in Sardinia, Italy, and P. marmoratus Burmeister, 1838 in Sicily, Italy] (Figs 1-22).

However, Bounechada et al. (2006) and Benkenana et al. (2012) have also listed P. marmoratus from Algeria, which Massa et al. (1993, 2012) consider as an endemic taxon to Sicily (Italy). For this reason, Massa (2013) suggested a more accurate comparison of specimens to ascertain the exact identity of the Algerian taxon. Specimens involved were collected during field work carried out in the North-East Algeria, in the area of Mila (Benkenana et al. 2012). During a visit by the first author to the laboratory of the second author in Palermo, it was possible to study carefully the Algerian specimens, to compare them with other species of Pamphagus and to confirm that they did not belong to any known species, neither Algerian or Sicilian. The aim of this paper is to describe this new species and to compare it with other known species of Pamphagus.

\section{Material and methods}

Specimens of species of the genus Pamphagus were studied and compared with the Algerian ones belonging to the unknown taxon; they are preserved in the following museums: Museum für Naturkunde, Berlin; Museo Nacional de Ciencias Naturales, Madrid; Museo Civico di Storia Naturale 'G.Doria', Genoa (MSNG); Muséum National 
d'Histoire Naturelle, Paris (MNHN); Natural History Museum, London; Naturhistorisches Museum, Vienna; National Museum Natural History, Prague; B. Massa Coll., University of Palermo (BMPC). A series of images of a number of specimens using different focal planes were taken by means of a Nikon Coolpix 4500 digital camera, mounted on a Stereomicroscope Wild M5, and integrated using the freeware CombineZP (Hadley 2008). Mounted specimens were measured using a digital calliper Digimax measy 2000 (precision $0.01 \mathrm{~mm}$ ); as precise measurement of wingless insects with large abdomen is difficult, the total body length was measured from the vertex to the apex of the hind femur. The total number of specimens measured is reported in Table 1.

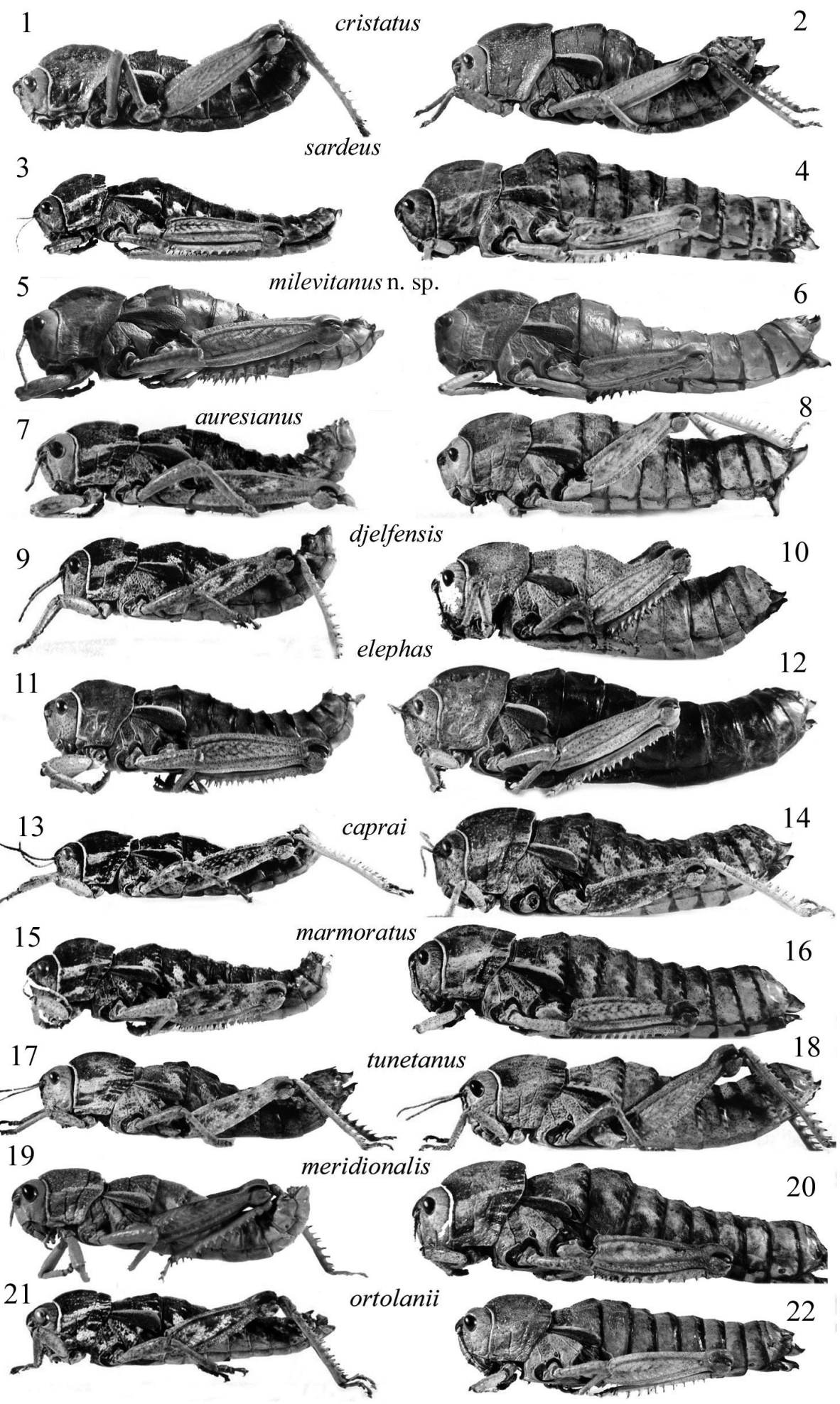

FIGURES 1-22. Overview of the species of the genus Pamphagus. 


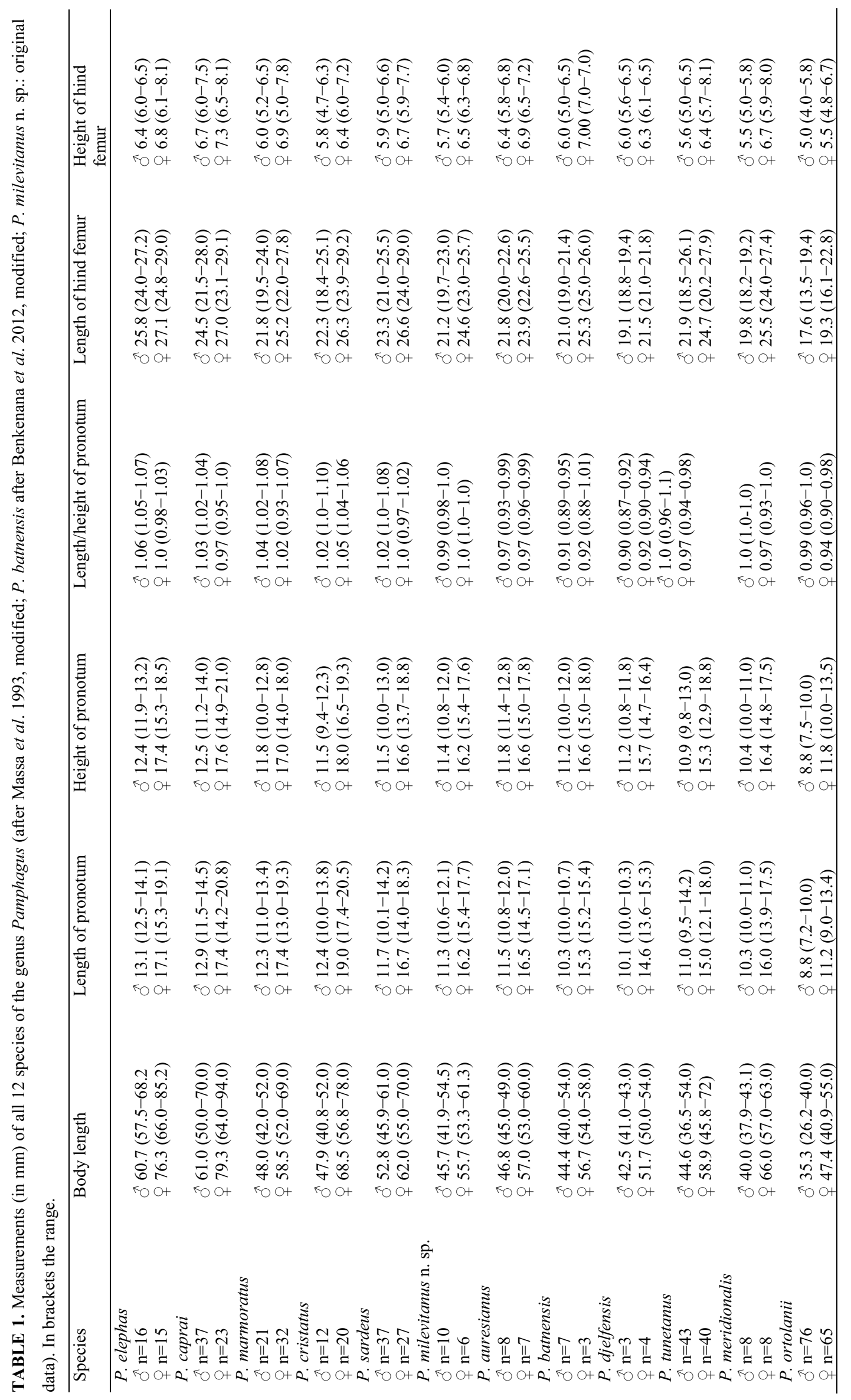



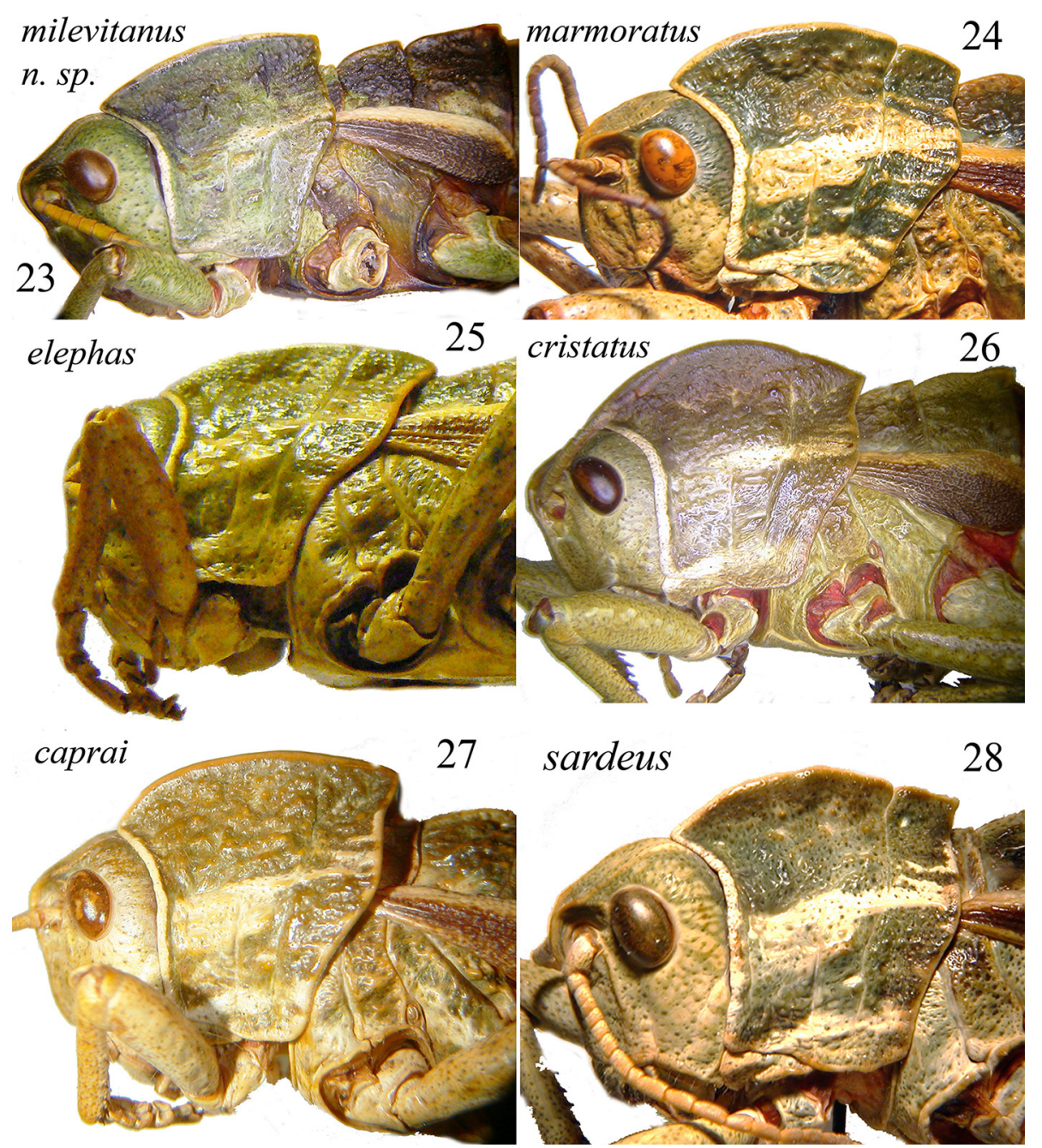

FIGURES 23-28. Lateral view of the head and pronotum of males of Pamphagus milevitanus $\mathbf{n}$. sp. (23) and the most related species $(24-28)$.

\section{Results and discussion}

\section{Pamphagus milevitanus new species}

(Figs 5-6, 23, 29, 35-36, 37, 50)

Material examined and type depository. Algeria, Mila, loc. Chigara 21.V.2016 ( $ð$ holotype); same data 9.V.16 († allotype) (MSNG); Algeria, Mila, loc. Chigara 8.V.2014 (1ð̄, 19 paratypes) (MNHN); Algeria, Mila, loc.

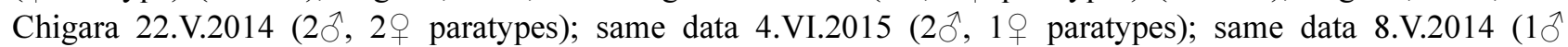
paratype); Algeria, Oum-el Bouaghi, Sigus 24.V.2016 (1 $\jmath^{\dagger}, 1 q$ paratypes) (BMPC).

Description. Male. Teguments rather smooth. Frontal ridge not projecting forward and compressed. Fastigium of vertex elongate, concave, limited by straight lateral carinulae. Antennae thick, 16-18 segmented, of which the first 7-8 with triangular section, others with circular section, as long as head and pronotum together; eyes oval. Median keel of pronotum high and raised, convex and laterally compressed, mainly in the dorsal portion, not or just interrupted by typical sulcus (Fig. 23). Dorsal posterior margin of metanotum and abdominal tergites, in lateral view, with a small tooth projection. Abdomen moderately carinate (Figs 5, 23). Krauss's organ smooth. Tegmina short, like in the other species of Pamphagus, not exceeding the metanotum. Prosternal tubercle characterized by a bulge that ends anteriorly with two pointed lobes; mesosternal space and metasternal space just wider than long. Last sternite very pointed, cerci conical and short (Fig. 35). Phallic complex, in lateral view, with long aedeagus (Fig. 37); aedeagus from back view stout and rhomboidal (Fig. 50); 3-4 large black pseudolophi (sensu Ünal 2014) of epiphallus, in single line, short ancorae (Fig. 37). 
Female. Same characters of the male with the following differences (Figs 6, 29). Larger size (Table 1). Pronotum protruding mainly anteriorly, less posteriorly, ratio length/height of pronotum: 1.0. Mesosternum just wider than long, metasternum 1.5-2 times wider than long. Ovipositor valves greenish, stout with slightly curved black tips. Cerci conical and pointed. Sub-genital plate rectangular, with a triangular lobe in the middle.

Colour. Green with yellow fore and dorsal margins of pronotum and abdominal carina. Ventral side of femora and inner side of tibiae yellow, tegmina blackish with yellow dorsal margin. Ventral side of tarsi blackish. Abdomen of the female less green than in male with posterior margin of tergites brownish.

Measurements. See Table 1. The ratio between the length and height of the pronotum is on average 1.0 both in males and in females.

Affinities. P. cristatus is the most related species to P. milevitanus $\mathbf{n}$. sp. Both species have a high pronotum, in most specimens the carina is not interrupted by a typical sulcus, and the abdomen is superiorly a little carinate. $P$. cristatus has a comparatively longer than high pronotum (ratio length/height: 1.1 on average); in addition there are evident differences in the phallic complex (Figs 40, 56). For a comparison with other species of the genus Pamphagus cf. Figs 1-4, 7-22, 24-28, 30-34, 38-46, 47-49, 51-56 and the key to species below reported.

Etymology. In antiquity Milevum was the Latin name of Mila; milevitanus is adjective.

Distribution. P. milevitanus n. sp. seems to occur only in the area of the highlands North and South of Constantine, in Mila, Setif and Oum-el Bouaghi provinces.
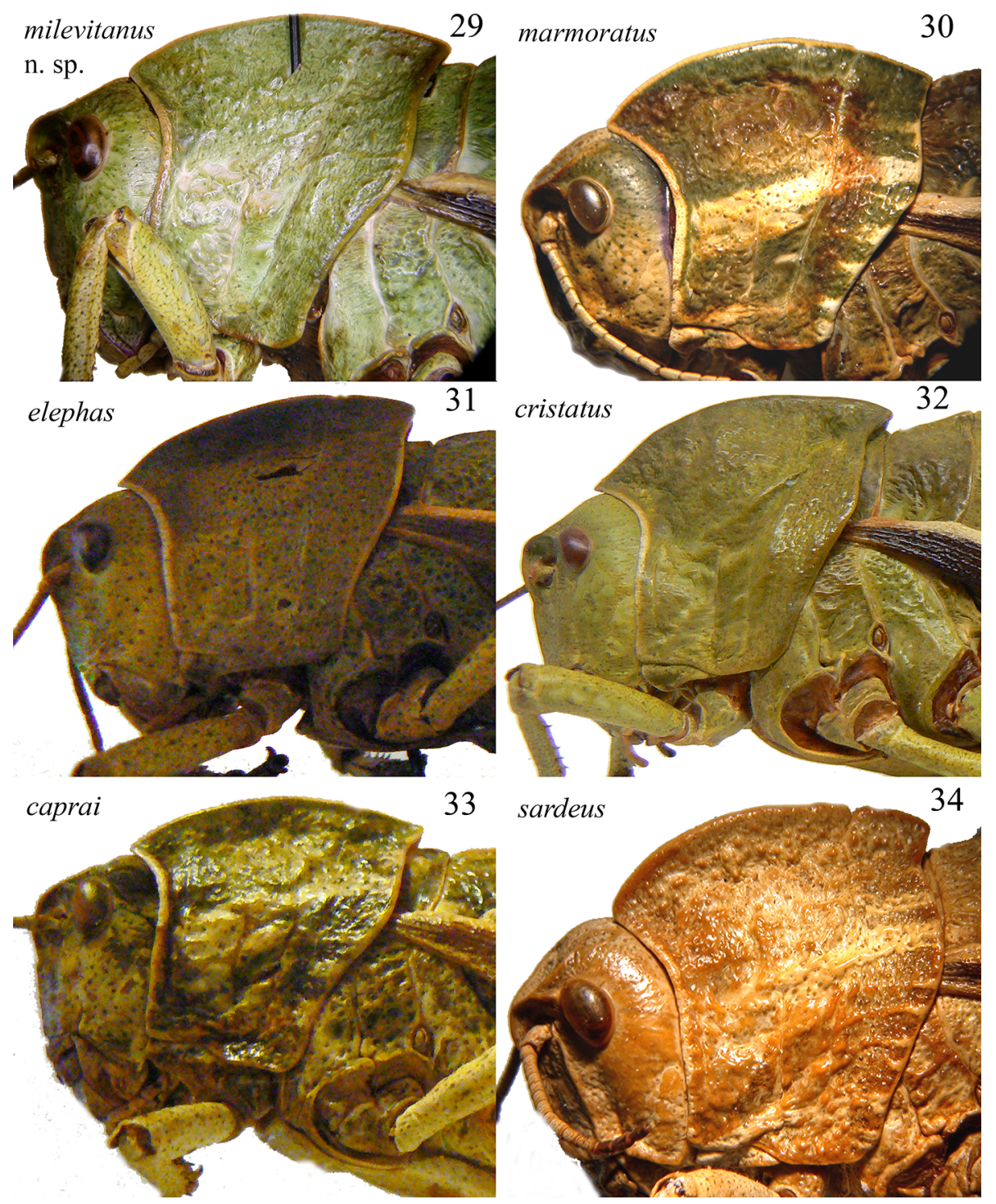

FIGURES 29-34. Lateral view of the head and pronotum of females of Pamphagus milevitanus $\mathbf{n}$. sp. (29) and the most related species $(30-34)$. 

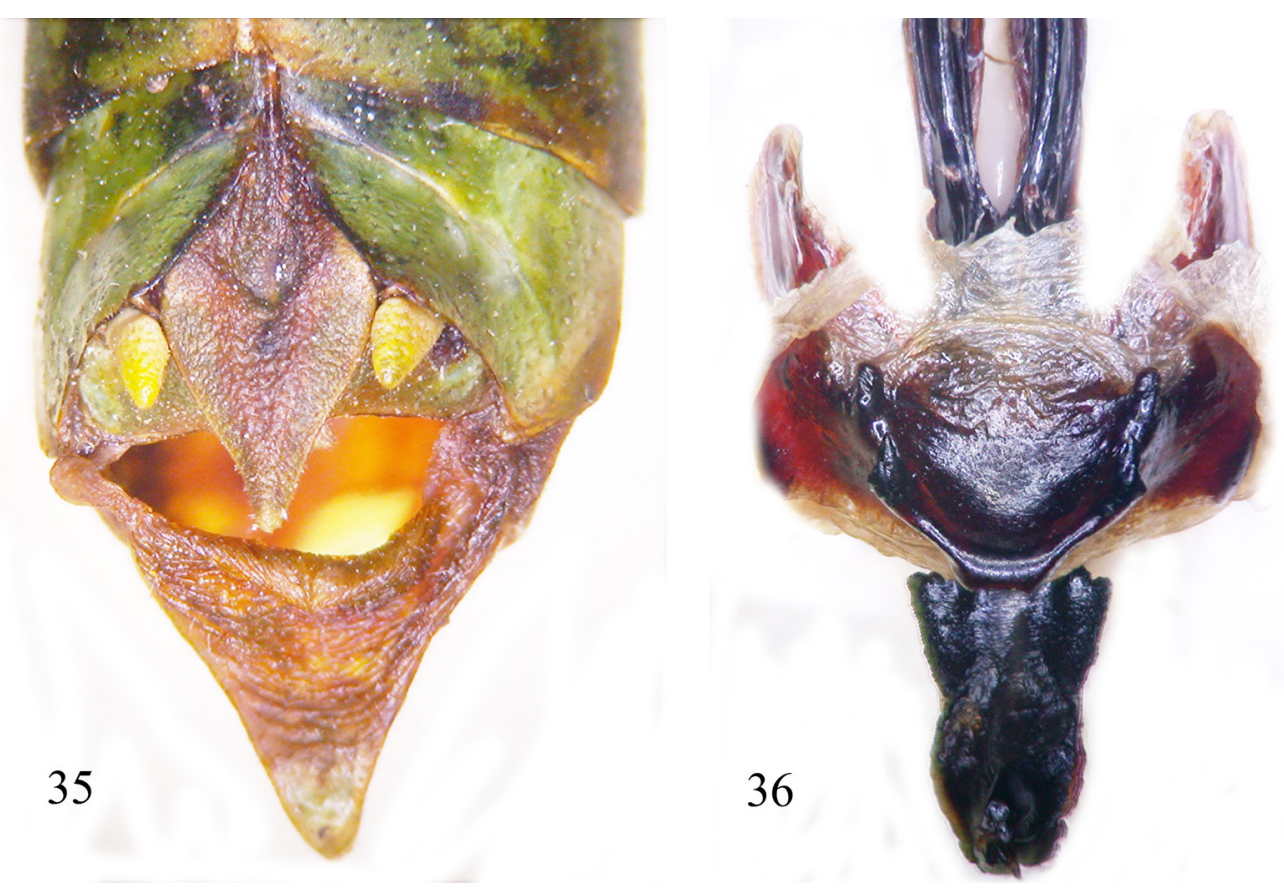

FIGURES 35-36. Dorsal view of the last tergites, cerci and the last sternite (35) and dorsal view of phallic complex of $P$. milevitanus $\mathbf{n}$. sp. (36).

\section{Conclusions}

Currently 12 species from the genus Pamphagus are known; seven of them live in Algeria, that very probably was the centre of diffusion of the genus into the Mediterranean. The present paper consents to exclude definitively the presence of $P$. marmoratus in Algeria and to confirm that it is an endemic taxon to Sicily.

\section{Key to species of the gen. Pamphagus}

(cf. also Table 1 and Figs 1-56)

This key works rather well for males, while if only females without males are available, their identification may result more problematic.

1. Pronotum in males and females raised and protruding backwards and forwards, laterally compressed (Figs 1-6, 11-16, 23-34); ratio length/height of pronotum mostly higher than 1.0. Tansverse sulcus interrupting or not interrupting the pronotum

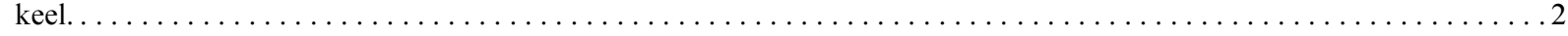

1'. Pronotum less raised and protruding, laterally not or scarcely compressed, mainly in males, less in females (Fig. 7-10, 17-22); ratio length/height of pronotum mostly lower than 1.0. Transverse sulcus (especially in males) interrupting the pronotum keel,

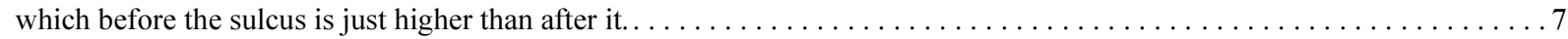

2. Transverse sulcus in males and in some females interrupting the pronotum keel (not always in females), but lateral sulcus always evident along the lobes of the pronotum, both in males and females. Pronotum protruding mainly anteriorly, less posteriorly. Krauss's organ smooth, roughly streaked, or finely streaked. Marbled coloration (also evident in old specimens). Tegu-

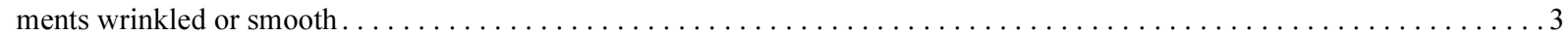

2'. Transverse sulcus not interrupting the pronotum keel and scarcely evident in the central part of its lateral lobes. Evenly green, with the exception of the upper edge of the pronotum, metanotum and tergites, generally cream (old specimens may be bleached, but they show an even coloration, not marbled). Pronotum protruding both anteriorly and posteriorly. Metanotum and first two tergites raised as a keel. Mostly smooth teguments. Krauss's organ roughly streaked in both sexes. Phallic complex not much curved (Fig. 39), epiphallus with many small spines arranged in two rows, aedeagus long, with a regular profile

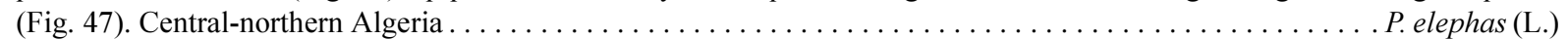

3. Larger size (length of body in males 50.0-70.0, in females 64.0-94.0). Cerci as long as wide at the base. First tergites show a 
small keel. Krauss's organ roughly streaked in both sexes. Phallic complex not much curved (Fig. 41), epiphallus with many pseudolophi arranged in two or three rows, aedeagus just laterally enlarged, with regular profile (Fig. 48). Green to brownishgrey, always marbled. Western Algeria and eastern Morocco. . . . . . . . . . . . . . . . . . P. caprai Massa

3'. Smaller size (length of body in males 41.9-61.0, in females 52.0-70.0). Cerci longer than wide at the base. The first two terg-

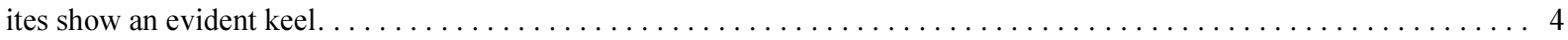

4. Teguments smooth. Pronotum much compressed laterally and smooth (Figs 3-4, 23). Krauss's organ smooth. Phallic complex not much curved (Fig. 37), epiphallus with few pseudolophi arranged in a single row per side (Fig. 36), aedeagus enlarged laterally (Fig. 50). Evenly green, not marbled. Inner Algeria (highlands North and South of Constantine, in Mila, Setif and Oum-

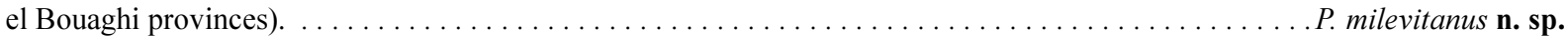

4'. Teguments more wrinkled. Pronotum less compressed laterally and more wrinkled. Green marbled. $\ldots \ldots \ldots \ldots \ldots \ldots$

5. Pronotum rarely interrupted by the transverse sulcus, metanotum and first tergites, mainly in males, with an evident keel (Figs $1-2,26,32)$. Krauss's organ smooth or finely streaked in both sexes. Phallic complex apically curved (Fig. 40), epiphallus with 1-3 large pseudolophi (Fig. 40), aedeagus laterally enlarged, with thin and crossed tips (Fig. 56). Green or marbled green. North-eastern Algeria and North-western Tunisia (Krumiria)................ . cristatus Descamps \& Mounassif

5'. Pronotum interrupted by transverse sulcus (mainly in males), metanotum and first tergites with a less evident keel (Figs 3-4, 15-16, 24, 28, 30,34). Krauss's organ smooth, roughly streaked or finely streaked. Phallic complex different (Figs 38, 42, 49,

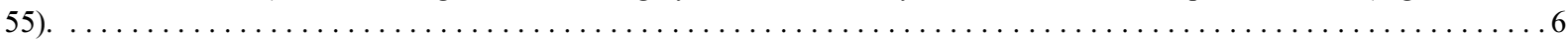

6. Krauss's organ wrinkled in males, finely streaked in females. Phallic complex not much curved (Fig. 38), epiphallus with very small pseudolophi, irregularly arranged, aedeagus long and with regular margins (Fig. 49). Green marbled. Central-western

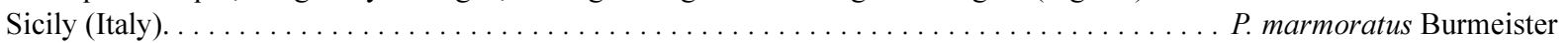

6'. Krauss's organ smooth in males, finely streaked or smooth in females. Phallic complex curved and broad (Fig. 42), epiphallus with some large pseudolophi arranged in one row per side, aedeagus broad and short, with an irregular profile (Fig. 55). Green marbled. Central-southern Sardinia (Italy). . . . . . . . . . . . . . . . . . . . . P. sardeus Herrich Schaeffer

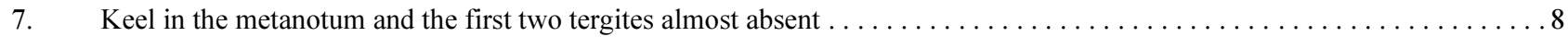

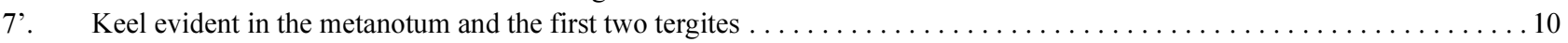

8. Carinae of vertex frontally closed by a more obtuse angle. Hind femora longer (in males 3.3, in females ca. 3.7 times longer

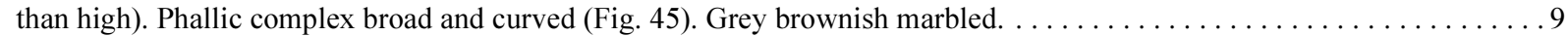

8'. Carinae of vertex frontally closed by a less obtuse angle. Hind femora shorter (in males 3.0, in females 3.3 times longer than high); hind femora and tibiae inside sprayed by carmine (especially in females). Phallic complex less broad and less curved (Fig. 43), epiphallus with small pseudolophi irregularly arranged, aedeagus with a double tipped base and pointed tip (Fig. 53). Grey reddish (males) or sand coloured (females). Djelfa, Hauts Plateaux, Algeria . . . . . . . . . . . P. djelfensis Vosseler

9. Epiphallus with small pseudolophi arranged in two rows, aedeagus broad, with a right angularly base (Fig. 51). Aurés Mts.,

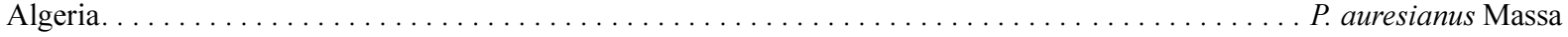

9'. Epiphallus with small pseudolophi confusedly arranged, aedeagus broad, with a rounded base (Fig. 52). Aurés Mts., Algeria.

.P. batnensis Benkenana \& Petit

10. Metasternal interspace in females between 2.0 and 3.0 times wider than long. Phallic complex curved, epiphallus with variable shape and number of pseudolophi, aedeagus not much broad, with a regular profile. Grey to brown marbled, very variable. Southern Tunisia. . . . . . . . . . . . . . . . . . . . . . . . . . . meridionalis Descamps \& Mounassif

10'. Metasternal interspace in females between 1.5 and 2.5 times wider than long. Epiphallus with large pseudolophi arranged in one row. Phallic complex much curved (Figs 44, 46). Grey to brownish or green marbled, very variable.. . . . . . . .

11. Larger size (body length in males 36.5-54.0, in females 45.8-72.0), hind femora ca. 3.8 times longer than high. Aedeagus broad with irregular profile (Fig. 54). Central-northern Tunisia and western Libya. . . . . . . . . . . P. tunetanus Vosseler

11'. Smaller size (body length in males 26.2-40.0, in females 40.9-55.0), hind femora ca. 3.5 times longer than high. Aedeagus more squared. Lampedusa Is., Sicilian Channel (Italy). .P. ortolanii Cusimano \& Massa

\section{Acknowledgements}

B. Massa received support from the Synthesys Project, which is financed by European Community Research Infrastructure Action under the FP7 "Capacities" Programme at the Naturhistorisches Museum, Vienna (2016: ATTAF-5324), the Museo Nacional de Ciencias Naturales, Madrid (CSIC) (2013: ES-TAF-2438), the Museum für Naturkunde, Berlin (2014: DE-TAF-4109) and the National Museum, Prague (2016: CZ-TAF-5559). We are especially indebted to Suzanne Randolf and Harald Bruckner (Naturhistorisches Museum, Vienna), Mercedes Paris (Museo Nacional de Ciencias Naturales, Madrid), Michael Ohl (Museum für Naturkunde, Berlin), Martin Fikáček (National Museum Natural History, Prague), Laure Desutter and Simon Poulain (Muséum National d'Histoire Naturelle of Paris), Roberto Poggi, Maria Luisa Tavano and Giuliano Doria (Museo Civico di Storia Naturale 'G. Doria', Genoa), who all facilitated the study of specimens preserved in their museums. We are also very much indebted to John J. Borg for the revision of the English language. 

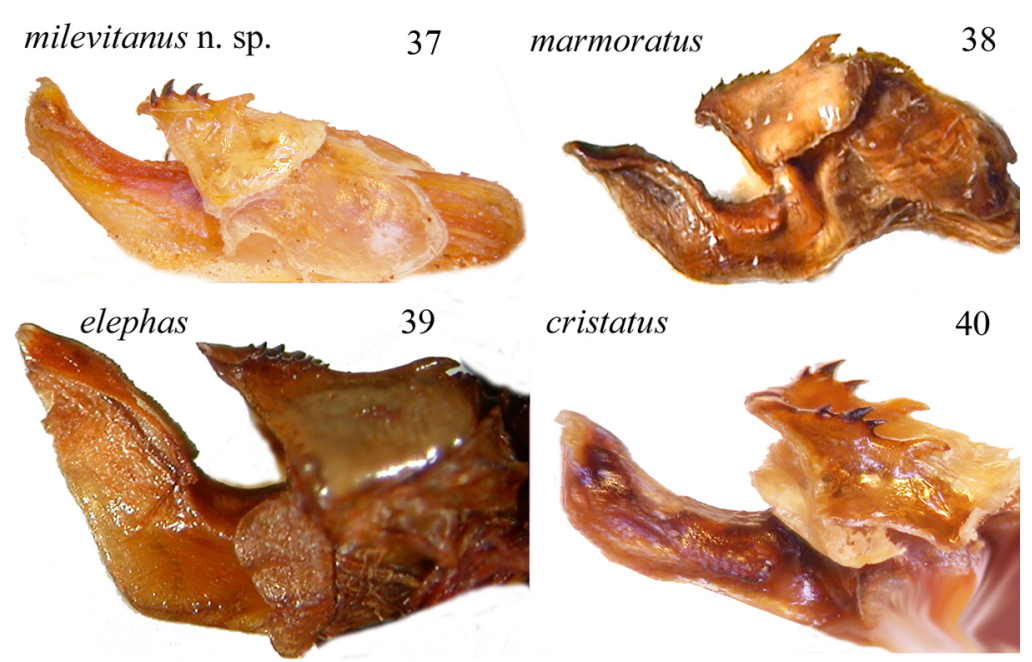

cristatus $\quad 40$
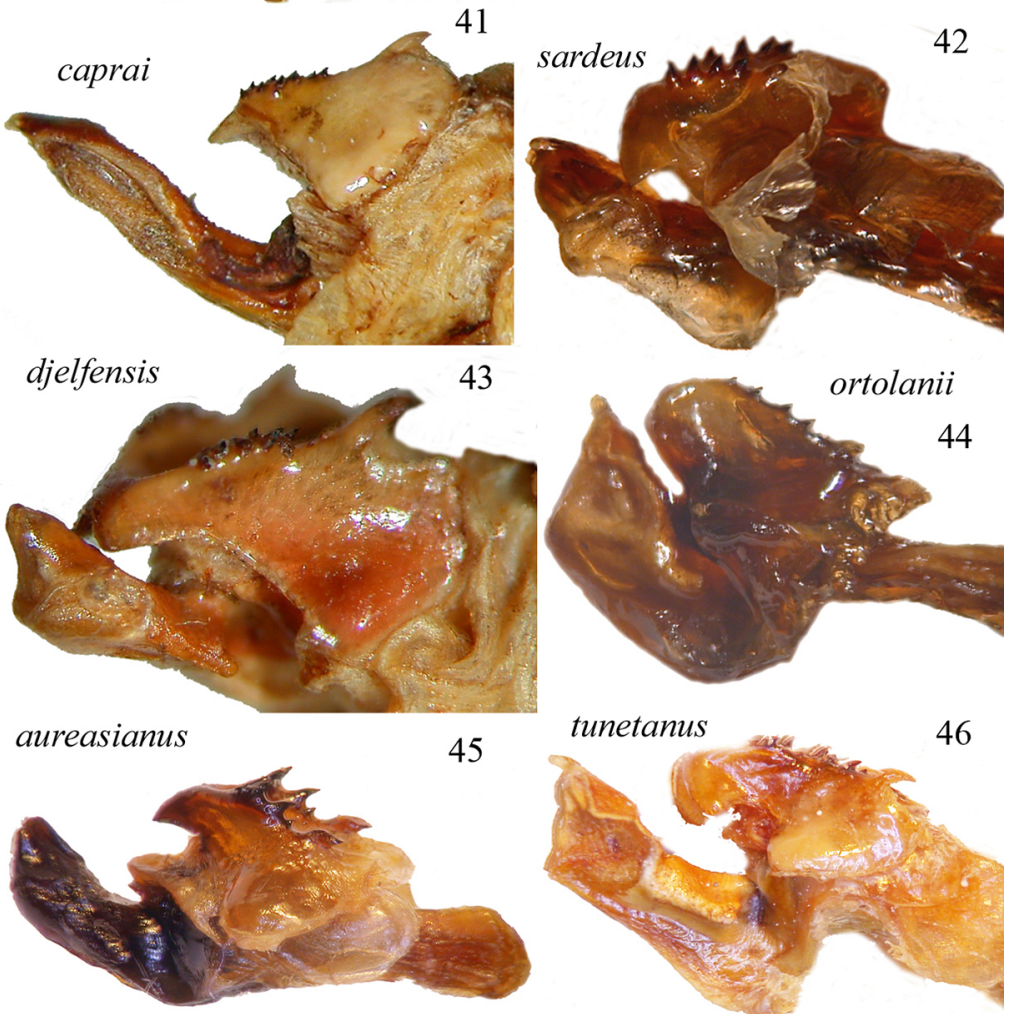

FIGURES 37-46. Lateral view of the phallic complex of $P$. milevitanus $\mathbf{n}$. sp. (37) compared to that of other species of the genus (38-46). 


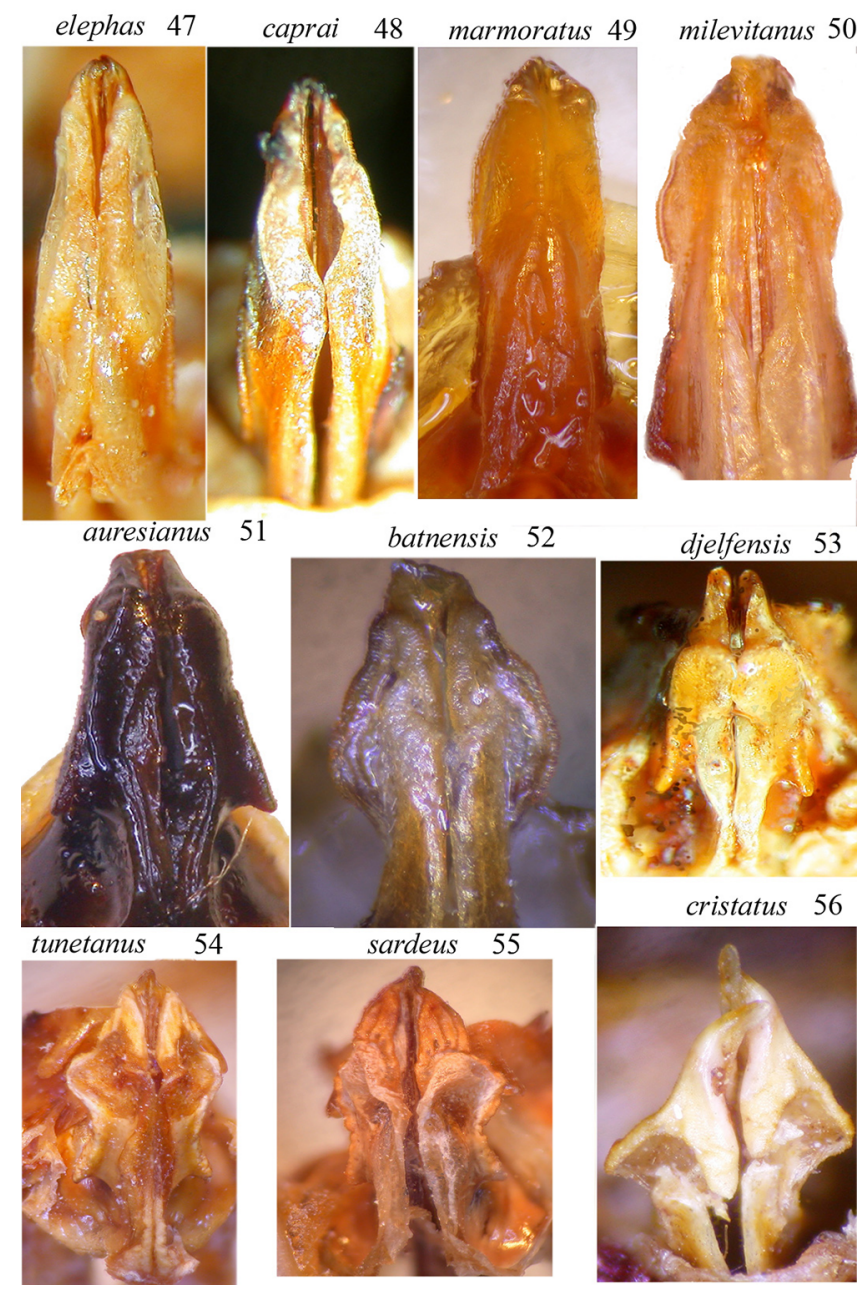

FIGURES 47-56. Back view of the apex of aedeagus of $P$. milevitanus $\mathbf{n}$. sp. (47) compared to that of other species of the genus (48-56).

\section{References}

Benkenana, N., Harrat, A. \& Petit, D. (2012) The Pamphagidae (Orthoptera) from East Algeria and description of a new species. Zootaxa, 3168, 22-38.

Bounechada, M., Doumandji, S.E. \& Çiplak, B. (2006) Bioecology of the Orthoptera species of the Setifian Plateau, North-East Algeria. Turkish Journal of Zoology, 30, 245-253. Avaliable from: http://journals.tubitak.gov.tr/zoology/issues/zoo-06-303/zoo-30-3-2-0502-4.pdf (Accessed 11 Apr. 2017)

Hadley, A (2008) Combine Z. Available from: http://www.hadleyweb.pwp.blueyonder.co.uk (accessed 20 February 2009)

Massa, B. (2013) Pamphagidae (Orthoptera: Caelifera) of North Africa: key to genera and the annotated check-list of the species. Zootaxa, 3700 (3), 435-475. https://doi.org/10.11646/zootaxa.3700.3.7

Massa, B., Fontana, P., Buzzetti, F.M., Kleukers, R. \& Odé, B. (2012) Fauna d'Italia. XLVIII. Orthoptera. Calderini, Bologna, $563+$ CCXIV pp.

Massa, B., Lo Valvo, M. \& Lo Verde, G. (1993) Le specie del gen. Pamphagus Thunberg 1815 (Orthoptera Pamphagidae). Bollettino del Museo regionale di Scienze naturali di Torino, 11, 445-486.

Ünal, M. (2014) A new species of Paranocarodes Bolivar, 1916 (Orthoptera: Pamphagidae) from Turkey . Journal of Insect Biodiversity, 2 (10), 1-10.

https://doi.org/10.12976/jib/2014.2.12 